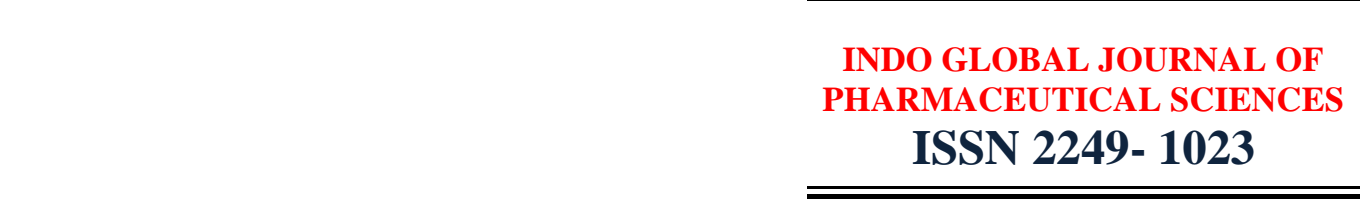

\title{
Essential Hypertension-A Review
}

\begin{abstract}
Received:
01.03.2019

Accepted:

25.03.2019

Keywords

HBP; Metabolic

Disorder;

Cardiovascular

Disorder.
\end{abstract}

\author{
Damanjit Kaur * \\ Sri Sai College of Pharmacy, Manawala, Amritsar-143115, Punjab, India
}

Address for Correspondence: Damanjit Kaur

\begin{abstract}
Hypertension (HTN) or high blood pressure, sometimes called arterial hypertension, is a chronic medical condition in which the blood pressure in the arteries is elevated. Blood pressure is summarised by two measurements, systolic and diastolic, which depend on whether the heart muscle is contracting (systole) or relaxed between beats (diastole). This equals the maximum and minimum pressure, respectively. Normal blood pressure at rest is within the range of $100-140 \mathrm{mmHg}$ systolic and $60-90 \mathrm{mmHg}$ diastolic. High blood pressure is said to be present if it is often at or above 140/90 $\mathrm{mmHg}$. Hypertension is classified as either primary (essential) hypertension or secondary hypertension. Hypertension puts strain on the heart, leading to hypertensive heart disease and coronary artery disease if not treated. Hypertension is also a major risk factor for stroke, aneurysms of the arteries (e.g. aortic aneurysm), peripheral arterial disease and is a cause of chronic kidney disease. Dietary and lifestyle changes can improve blood pressure control and decrease the risk of health complications, although drug treatment is still often necessary in people for whom lifestyle changes are not enough or not effective. (C) 2019 iGlobal Research and Publishing Foundation. All rights reserved.
\end{abstract}

Cite this article as: Kaur, D. Essential Hypertension- A Review. Indo Global J. Pharm. Sci., 2019; 9(2Suppl.): 133. DOI: http://doi.org/10.35652/IGJPS.2019.92S31 .

Indo Global Journal of Pharmaceutical Sciences( ISSN 2249 1023; CODEN- IGJPAI; NLM ID: 101610675) indexed and abstracted in CrossRef (DOI Enabling), UGC CARE Journal List, EMBASE(Elsevier), National Library of Medicine (NLM) Catalog, ResearchGate, Publons, CAS (ACS), Index Copernicus, Google Scholar and many more. For further details, visit http://iglobaljournal.com

This is a special issue as an outcome of 'RAPSCON-2019' sponsored by APTI and organized by Sri Sai College of Pharmacy, Manawala, Amritsar, Punjab, India. Relaxation offered in journal format. 